\title{
Trichostrongylus orientalis
}

National Cancer Institute

\section{Source}

National Cancer Institute. Trichostrongylus orientalis. NCI Thesaurus. Code C125970.

A species of parasitic roundworms in the family Trichostrongylidae that is most prevalent in Asian countries. 